\title{
APONTAMENTOS SOBRE A POESIA DE MANUEL DE FREITAS
}

\author{
Danilo Bueno ${ }^{1}$
}

RESUMO: Este artigo pretende apontar e problematizar algumas características da poesia de Manuel de Freitas, notadamente a defesa de uma "poesia sem qualidades", contextualizando-a com tendências poéticas portuguesas das últimas décadas.

PALAVRAS-CHAVE: Poesia sem qualidades, década de 60 a 80, cânone, real.

ABSTRACT: This article intends to demonstrate and discuss some characteristics of Manuel de Freitas's poetry, namely the defense of a "poetry without qualities", contextualizing it within the Portuguese poetic trends of the latest decades.

KEYWORDS: Poetry without qualities, decades of the 1960 s to 1980 s, canon, real.

Manuel de Freitas tem vários livros publicados, desde pequenas plaquetes quase caseiras até livros de maior circulação. Entre eles destacam-se: [SIC] (2002), Beau Séjour (2003) e o recente Intermezzi, op. 25 (2009). Além desses livros de poemas, Freitas é o organizador da antologia Poetas sem qualidades (2002) e publicou um ensaio sobre a poesia de Al Berto: Me, Myself and I (2005). No Brasil, há uma antologia dedicada aos seus poemas: Manuel de Freitas 1 (2007). Nota-se, portanto, uma produção já extensa e com participação ativa na poesia portuguesa contemporânea.

No entanto, foi pela referida antologia dos Poetas sem qualidades que a poesia de Freitas, e sua visão crítica, ganharam espaço de discussão e interesse. Decerto que pressupor esse parâmetro como regra de leitura incorre-se no risco de generalizar, sob um aspecto centralizador, uma obra em transformação de um poeta jovem; entretanto, é a partir dessa característica que exsurge uma proposta de interesse para o acervo da poesia contemporânea portuguesa.

Entender o significado do termo "sem qualidades" demandaria um aporte cuja direção apontaria, certamente, para um viés ético-político, antes mesmo do que estético. Trata-se, sobretudo, de uma operação de releitura do cânone, sem condescendência, colocando também a recepção poética em pauta ao conclamar o leitor para um imaginário estritamente arraigado no tempo de hoje, através de um processo de despoetização progressiva cujo mérito é chamar a atenção para outras possibilidades do

\footnotetext{
${ }^{1}$ Mestre em Letras - Universidade de São Paulo.
} 
imaginário poético.

Essa poesia dita "sem qualidades" é construída por meios que ironizam e criticam a sensibilidade poética convencional, como o uso de metáforas automatizadas e o apelo poético gratuito, cujo emprego, muitas vezes, coloca a enunciação em um universo elevado e etéreo, deslocado das discussões cotidianas, alheando-se das questões do comezinho, que em um mundo dessacralizado pode ser o lugar dos grandes voos. É justamente do "comezinho" que a poesia de Manuel de Freitas quer tratar, conforme o prefácio:

A questão que hoje se coloca - em Portugal, que é onde estamos prende-se sobretudo com o apreço "qualitativo" por anacronismos e ourivesarias e com o resto. Esta antologia, que não foi subsidiada nem gastou solas do Parnaso, pretende contemplar isso mesmo: o(s) resto(s) (FREITAS (org), 2002, p. 12).

Nota-se que Freitas faz questão de determinar o lugar geográfico-político de sua enunciação: Portugal. Tal introdução discursiva remete à expressão-título “consequência do lugar" escrita por Joaquim Manuel Magalhães, cujo significado parece apontar para a crença de que a linguagem se dá no momento e no lugar do seu uso, como descreveu Wittgenstein, semelhante a uma prática que fosse descobrindo seus próprios mecanismos ao mesmo tempo de sua feitura, e, justamente por esse motivo, impusesse a inescapável condição ética de se falar do lugar em que se está, ainda que a heteronímia tenha dissipado qualquer rastro de sinceridade e de elocução confessional de um "eu" determinante, é improvável suprimir a coação do tempo e a circunscrição física do real, sendo que o poeta se depara, repetidamente, com a face plena do devir. A poesia de Manuel de Freitas é sensível ao conhecimento do seu próprio lugar de fala.

No entanto, se engana quem porventura cogite que se trata de uma poesia sem sofisticação ou sem camadas de significação. Os poemas percorrem questões nodais como o amor, a morte, o tempo, temas ancestrais do tecido linguístico. Nesse sentido, Rosa Maria Martelo observou "que uma das características da poesia mais recente passa pela existência de processos de sobrecodificação que permitem explorar vários níveis de leitura (MARTELO, 2004, p. 250)”. Não só um leitor médio poderá entender e fruir dessa poesia como também um leitor especializado, pois há, no fundo, uma questão estética determinada a ser discutida que pode ser aduzida, grosso modo, no seguinte impasse: Quais recursos poéticos, hoje, na época voraz do relativismo técnico da "pósmodernidade", podem indicar uma qualidade efetiva, mais atinente e pertinente ao real? 
Chega-se, portanto, a uma questão política bem pontilhada nessa busca, pois se intenta resgatar o leitor que já não se interessa pela tecnicidade do discurso poético, que levado às últimas consequências pelas vanguardas no século XX tornou-se muitas vezes auto-referencial, traçado pelo incessante embate estético de superação e ruptura. Além disso, a proposta de tornar o real outra vez real, capitula em si mesma o diálogo com o imaginário português, como se novamente pudéssemos escutar o refrão que conclui o livro Mensagem, de Fernando Pessoa: “É a Hora!” (PESSOA, 2008, p. 126), ou seja, o chamado para a reconstrução da identidade pátria, entre o sujeito lírico e o político. Sobre este tópico, anotou Luís Maffei:

Desse modo, trazer a realidade para a poesia talvez seja o único modo
possível, hoje em dia, de se realizar um tipo de matrimônio há muito
desfeito, pois há muito o vate já não representa seu grupo, desde
longa data o real, sobretudo no que tem de quotidiano, mostra-se
inacessível à poesia, pois a ela é hostil. Assim sendo, a re-união de
poesia e realidade dá-se, tão-somente, se a primeira convidar a
segunda, já que o contrário não ocorrerá (MAFFEI, 2005, p. 156).

Esse comprometimento com o real, que remonta a Joaquim Manuel Magalhães, de acordo com o arquicitado poema "Princípio" publicado como abertura do livro Os dias, pequenos charcos, de 1981, que postulava: "Voltar ao real, a esse desencanto/ que deixou de cantar..." (MAGALHÃES, 1981a, p. 13). Essa tendência de retorno ao real surgiu, principalmente, mas não só, em reação à pesquisa de linguagem efetuada pela Poesia 61. A poesia portuguesa teve um renascimento nos anos 60 , conseguindo alçar outros caminhos, já menos sufocada pela onipresença de Fernando Pessoa:

Ser-nos-ia, então, possível falar de dois grandes períodos da poesia portuguesa posterior a Fernando Pessoa e a um modernismo que nasceu e morreu com ele: um de 1935 a 1960 e outro de 1961 aos nossos dias (NAVA, 2004, p. 193).

Nava circunscreve entre 1935 e 1960 a geração de Jorge de Sena, Eugênio de Andrade e Sophia de Mello Breyner, poetas de relevo que souberam dimensionar o legado pessoano com originalidade, para depois delimitar a Poesia 61, que fez dos anos 60 uma década rica e multifacetada, com a exigência da contenção formal orientada por um obstinado refinamento de escrita, com Fiama Hasse Pais Brandão, Luiza Neto Jorge e Gastão Cruz.

Além da Poesia 61, houve ainda a POEX, que se interessava por experiências radicais, utilizando vários suportes e mídias, influenciada pela poesia concreta brasileira 
e pela poesia barroca, tendo como expoentes E. M. de Melo e Castro e Ana Hatherly. A $P O E X$, talvez pela sua explícita filiação com o contexto brasileiro, não foi muito bem acolhida em Portugal, sendo alvo de críticas muitas vezes despropositadas, vide o chiste de Ruy Belo, utilizado por Luís Miguel Nava para expor a Poesia 61:

[...] a poética desses autores caracterizar-se-ia, contudo, pelo estabelecimento, no interior do próprio texto, de uma cerrada rede de relações que a afastaria dos experimentalistas, o que levou Ruy Belo, não sem alguma ironia, a definir Poesia 61 como uma 'coletânea que além do seu mérito intrínseco, teve a virtude de evitar que entre nós houvesse poesia concreta' (NAVA, 2004, p. 213).

A visão de que a poesia concreta poderia ser algo esteticamente nocivo está implícita na afirmação estigmatizante de Ruy Belo, ele mesmo um poeta excepcional e aberto às múltiplas virtualidades da língua, mais ainda adstrito a uma visão limitada da proposta da poesia concreta brasileira. O fato das plaquetes da Poesia 61 terem se desenvolvido "pelo estabelecimento, no interior do próprio texto, de uma cerrada rede de relações" não determina, por negação, que a poesia concreta, ou sua seguidora, a POEX, fossem menos consistentes ${ }^{2}$.

Após a rica fatura dos anos 60 , portanto, a poesia portuguesa tendeu, nos anos 70 e 80 , a outras pesquisas, já conscientes de que o domínio estrito da linguagem não poderia ser um diferencial solitário para encabeçar um movimento poético. A poesia buscava um testemunho que aderisse a fala poética ao desconcerto do mundo e devolvesse um senso de realidade para uma poesia que também poderia se situar nos meandros da linguagem, lembrando o posicionamento testemunhal de Jorge de Sena. Volta-se a Joaquim Manuel Magalhães, conforme o referido "regresso ao real" e podese adicionar Al Berto, cuja aproximação entre linguagem e vida assume contornos autobiográficos definidos, numa performance de escrita excessiva, que teatraliza a vida, conferindo-a outras realidades, ou, ainda, como definiu Manuel de Freitas: "uma toxicodependência verbal (FREITAS, 2005, p. 25)".

Pode-se arriscar de que a poesia de Manuel de Freitas, de acordo com a parecença com os autores citados, assume o encargo de resgatar o leitor para o Mundo, no sentido mais conceitual e filosófico dessa expressão. Uma de suas estratégias é poetizar um mundo mais pedestre, e para isso usa frequentemente a metáfora da boêmia para traçar a vigilância e a meditação do espírito que interroga seguidamente sua

\footnotetext{
${ }^{2}$ Trata-se de um julgamento arbitrário da proposta concretista, pois seria o caso de se definir com precisão o significado da expressão "cerrada rede de relações", que enseja inúmeras argumentações e desdobramentos.
} 
própria função, e que se circunscreve constantemente por aflições existenciais e financeiras. O poema abaixo ilustra essa proposta:

Por esses e outros motivos

[para o José Miguel Silva]

Essência? Só se for a gasolina.

Para Heidegger, Leibniz ou Espinoza

era eu na altura demasiado novo

e agora (devo confessá-lo) demasiado

velho. O mundo, estou em crer,

não passa ou não quer passar

por esses solenes alçapões do sentido.

Sistemas, teorias, relógios tão parados.

Nascemos (é um azar comum),

Envelhecemos mal, temos dúvidas

e dívidas sobre as quais ninguém

- mesmo que se lhe chame Deus -

responde. Ou até filhos parecidos,

emblemas da matéria provisoriamente

nos devolvem o nariz adunco,

um sinal, a morte tatuada e certa.

Coisas que remendem o melhor dos mundos.

Eu (devo confessá-lo?) tenho passado bem

sem filosofia e sem emprego. Não corro

aos púlpitos disponíveis, não protesto

- e prefiro passa fome de gin quando o restaurante

que me espera se traduz em várias línguas.

É por esse e outros motivos

que não gosto assim tanto

dos poetas meus contemporâneos.

(FREITAS, 2002, p. 19-20). 
Logo na primeira estrofe, há uma oposição bastante clara entre uma apreensão essencialista do mundo e uma visão mais pragmática, fixada na existência. Pode-se supor que o sujeito poético não está interessado em volteios metafísicos, nem em especulações acerca da constituição universal dos seres, mas, e de maneira frontal, procura se concentrar na realidade, ainda que dizer realidade, termo que continuadamente é utilizado aqui, e que enseja, em alguma outra oportunidade, uma elucidação mais detida; seja absolutamente complexo e demande inúmeras especulações, não há modo mais apropriado para denominar seu desprezo pela busca de algo que possa ser a descrição ou o fundamento de qualquer verdade.

Trata-se de uma escrita que busca a afirmação da experiência e da comunhão com um igual, antes de sua conversão em leitor. A massa sonora do poema mimetiza esse caminho: o tom é mais afeito a uma conversa trivial do que a um discurso ou a uma declamação: "Vamos falar limpo, agora" (FREITAS, 2002, p. 19-20) escreve-se em outro poema, como se deixasse às claras toda a possibilidade de comunicação, como se o trajeto confissão-comunhão-pacto se estabelecesse. Pode-se depreender o preterimento da eufonia, no sentido estrito do termo, para se alçar uma musicalidade quase isenta de retórica recitativa. Essa operação, fruto da construção e da elaboração, perfaz a fluidez de um "ritmo falado", que demanda a justeza de cavalgamentos: "Eu (devo confessá-lo?) tenho passado bem/ sem filosofia e sem emprego. Não corro/ aos púlpitos disponíveis, não protesto [...]". Nota-se, nestes três versos, a opção pela quebra sintática para sincopar a respiração do poema, deixando-o em tom menor para que o leitor se sinta o interlocutor privilegiado do poeta.

Dessa forma, pode-se falar de uma audição particular, privativa, gerada pelo enlace poeta/leitor: como se resgatados pela musa, que já alçou longos barcos na extensa tradição literária portuguesa, e, agora, (porquê não?), transforma o bar em leme em direção à subjetividade mais enraizada do cidadão português?

O poema desdenha das teorias, pois o possível é, acima de tudo, a errática existência: "a poesia como um modo de vida" (cf. BARRENTO, 2006, p. 59), ou seja, uma espécie de realismo, que não é engajado, mas atencioso e vigilante e aposta na inalienabilidade do corpo como emblema disposto a arcar com a execução do próximo poema. A fatalidade da existência torna a escrita a opção verossímil frente à desistência completa do mundo.

Trata-se, ainda, de um poema metacrítico que avalia negativamente a poesia 
contemporânea ao sugerir uma estrutura de "capelinha": "Não corro/ aos púlpitos disponíveis, não protesto [...]". Manuel de Freitas parece querer se situar bem distante de qualquer glamour ou postura literária oficial, como se o mundo literário, no sentido mercadológico, tivesse que ser reinventado, pois parece ter construído a sua própria estrutura de poder e espetáculo, não sendo exatamente o lugar apropriado para se buscar uma preocupação mais profunda com a poesia, já que ser contemporâneo de algo implica em muitos fatores que não podem ser reduzidos aos interesses mercadológicos.

E a crítica a esse mundo tarifado vem na própria estrutura do livro [SIC] (2002), dividido em seções como se simulasse o período de estadia em uma taverna, um happy hour metropolitano, talvez barulhento e desencantado. O poema em análise foi retirado da primeira parte "Horário de Funcionamento", que é seguida por "Consumo obrigatório" e "Livro de Reclamações". Note-se, e aí uma sutileza aparece: o título [SIC] faz uso do termo usado para que se leia determinada palavra exatamente do jeito que está escrita, a despeito de imprecisão ou erro evidente, sendo propositalmente ambíguo. Trata-se de indicar uma intencionalidade literal: o mundo como está escrito. Assim, a tessitura do livro se fecha, pois o caderno de reclamações do poeta deve ser lido sem espessamento metafórico, estratégia que intensifica a analogia e a mimese do real.

Jorge Fernandes da Silveira, a propósito da poesia de Joaquim Manuel Magalhães, apontou um interessante mecanismo pelo qual essa mesma escolha poética se desenvolve, podendo-se estender essas palavras aos escritos de Freitas, conforme se lê:

Assim, quando digo que o livro "apresenta" o seu discurso, ao invés de representá-lo, quero dizer que nos poemas há literalmente uma crise da representação, já que neles, do processo de escrita ao de leitura, o sistema de recepção, em suma, vem inscrito o mal de não ver mais na coerência, construída ou inventada da alta literatura, ou melhor, do alto trabalho poético, uma hipótese de reparação para os desconcertos do mundo (SILVEIRA, 2003, p. 32).

Da alta literatura para o banal e o panfletário, da representação para a apresentação pura e simples de um contexto. É do banal, e do baixo volume da lira um dos caminhos para a escrita portuguesa.

Não se pode responder com segurança se a maneira como vem se desenvolvendo a poesia de Manuel de Freitas atende cabalmente à problemática já 
aludida: descobrir meios para a figuração de uma qualidade efetiva. No entanto, as tentativas, além de criativas, por dimensionarem com propriedade as tendências da tradição recente portuguesa, são bastante construídas, a ponto de se pensar que a ausência de qualidade não demandaria, por vezes, mais perícia e engajamento estético, do que a automatização lírica da qual se revestem algumas opções de escrita mais ortodoxas.

Talvez a resposta para essa delicada equação poética seja considerar a profundidade dessas palavras de Wallace Stevens: "One function of the poet at any time is to discover by his own thought and feeling what seems to him to be poetry at that time" (STEVENS apud MAGALHÃES, 1981b, p.7). Buscar na escrita a aferição e a existência da própria escrita, com ou sem qualidades, e que de alguma maneira possa delinear o espírito desse tempo, decaído e multi-informático, mais que, todavia, também irá passar.

\section{BIBLIOGRAFIA:}

BARRENTO, João. O arco da palavra. São Paulo: Escrituras, 2006.

FREITAS, Manuel (org.). Poetas sem qualidades. Lisboa: Averno, 2002.

FREITAS, Manuel. Beau Séjour. Lisboa: Assírio Alvim, 2003. . Intermezzi, op.25. Guimarães: Opera Omnia, 2009. . Me, Myself and I. Lisboa: Assírio Alvim, 2005. . [SIC]. Lisboa: Assírio Alvim, 2002.

MAFFEI, Luís. "Os Poetas Sem Qualidades: em busca da contemporaneidade possível” Revista de Letras Unesp, São Paulo, 45 (1): 151 - 171, 2005.

MAFFEI, Luís (org.). Manuel de Freitas 1. Rio de Janeiro: Oficina Raquel, 2007.

MAGALHÃES, Joaquim Manuel. Os Dias, Pequenos Charcos. Lisboa: Editorial Presença, 1981a.

.Os dois crepúsculos - Sobre poesia portuguesa actual e outras crónicas. 
Lisboa: A regra do jogo, 1981b.

MARTELO, Rosa Maria. Em parte incerta - Estudos de poesia portuguesa moderna e contemporânea. Lisboa: Campo de Letras, 2004.

NAVA, Luís Miguel. Ensaios Reunidos. Lisboa: Assírio Alvim, 2004.

PESSOA, Fernando. Mensagem. Rio de Janeiro: 7Letras, 2008.

SILVEIRA, Jorge Fernandes da. Verso com verso. Coimbra: Angelus Novus, 2003. 